\title{
A Comparison of Health Care Resource Utilization and Costs for Patients with Allergic Rhinitis on Single-Product or Free-Combination Therapy of Intranasal Steroids and Intranasal Antihistamines
}

\author{
Brooke Harrow, PhD; Ahmad R. Sedaghat, MD, PhD: \\ Amanda Caldwell-Tarr, PhD; and Robert Dufour, PhD
}

\begin{abstract}
BACKGROUND: Allergic rhinitis (AR) is a common condition that can be treated with a number of different therapies. Treatments such as intranasal antihistamines (INAs) and intranasal steroids (INSs) are widely used by AR patients. For some allergy sufferers, a combination of therapies, specifically an INA and an INS, is required to address their symptoms. A new treatment, the formulation of azelastine hydrochloride and fluticasone propionate used as a single spray (MP-AzeFlu), has become available for AR patients who need both types of treatment. In this regard, the comparison with the alternative concomitant use of INAs and INSs is of interest. The current study examines the health care resource utilization and costs for each cohort.
\end{abstract}

OBJECTIVE: To examine the resource utilization and costs associated with AR for patients treated with MP-AzeFlu or concurrent therapy with singleingredient INA and INS sprays (free-combination therapy).

METHODS: A retrospective administrative claims study for commercially insured patients from a large U.S. health plan was performed. Patients with an AR diagnosis and a prescription claim for MP-AzeFlu or free-combination therapy between September 1, 2012, and September 30, 2013, were identified. Patients were aged at least 12 years at index date (first prescription fill for intranasal therapy) and were required to have 12 months preindex and 6 months post-index of continuous enrollment. Health care resource utilization and costs were assessed for the post-index period. The cohorts were adjusted on baseline demographic and clinical characteristics using inverse propensity treatment weights. Other covariates, prescriber specialty, product switching during the post-index period, and pre-index total costs were included in the regression models measuring outcomes. One clinical characteristic of interest was the presence of asthma as comorbidity. A subset analysis of AR patients with asthma was also performed.

RESULTS: All-cause-related pharmacy fills as well as pharmacy, medical, and total costs were significantly reduced by using MP-AzeFlu $(\mathrm{N}=810)$ instead of the free combination of drugs $(\mathrm{N}=726)$. For AR-related health care resource utilization, the MP-AzeFlu cohort had significantly fewer pharmacy fills than the free-combination cohort (1.01 and 1.17, respectively; $P<0.001)$ with no significant difference in outpatient services and specialist visits $(P=0.139$ and $P=0.117$, respectively). Six-month AR-related pharmacy and total costs were significantly lower $(P<0.001$ and $P=0.001)$ for the MP-AzeFlu cohort ( $\$ 128$ and $\$ 334$, respectively) than the free-combination cohort (\$268 and $\$ 458$, respectively). There was no statistically significant difference in AR-related medical costs between the 2 cohorts $(P=0.454)$. For the subcohort of AR patients with asthma, the MP-AzeFlu cohort had lower 6-month asthma resource utilization and costs than the free-combination cohort.

CONCLUSIONS: These findings suggest that, for AR patients needing INAs and INSs, the single-spray formulation MP-AzeFlu had better economic outcomes than for patients who rely on the free combination of these agents. MP-AzeFlu also appears to keep asthma-related utilization and costs down for those AR patients who also suffer from asthma. Potential explanations for these findings are explored.

J Manag Care Spec Pharm. 2016;22(12):1426-36

Copyright $\odot 2016$, Academy of Managed Care Pharmacy. All rights reserved.

\section{What is already known about this subject}

Allergic rhinitis (AR) is one of the most common chronic conditions in the United States, with close to $38 \%$ of patients also suffering from asthma.

Successful management of AR can be a challenge and can lead to dissatisfaction with the more common pharmacotherapies (intranasal steroids [INSs] or intranasal antihistamines [INAs]).

MP-AzeFlu is a safe and effective treatment of AR in patients who require dual therapy with an INS and an INA.

\section{What this study adds}

This study compared MP-AzeFlu with free-combination therapy and examined the use of MP-AzeFlu and its effect on health care resource utilization and costs for patients with AR and those with concurrent asthma.

AR patients prescribed MP-AzeFlu had similar or less utilization than patients taking a combination of INA and INS drugs (free combination); pharmacy costs and total costs were lower for patients on MP-AzeFlu, while AR-related medical costs were similar to those on the free combination of therapies.

For AR patients also diagnosed with asthma, those prescribed MP-AzeFlu had similar use of emergency department services, outpatient services, and specialist visits, but significantly fewer pharmacy fills than those prescribed a free combination of INA and INS products.

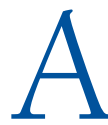
llergic rhinitis (AR), characterized by sneezing, nasal congestion, nasal itching, and rhinorrhea, is one of the most common chronic conditions in the United States, affecting approximately $22 \%$ of adults and up to $40 \%$ of children. ${ }^{1-4}$ The prevalence of AR has been on the rise for many years, and it is currently the sixth most common chronic disease in the United States, leading to $\$ 18$ billion of medical costs annually. ${ }^{5}$

Not surprisingly, AR has a significant detrimental impact on the quality of life of afflicted individuals as well as leading to substantially increased health care costs. ${ }^{6-9}$ Asthma is a common comorbid condition in patients with AR. ${ }^{10}$ In the United States, up to 38\% of AR patients suffer from asthma, and as many as $90 \%$ of patients with asthma suffer from 
concurrent AR. ${ }^{2}$ It is unclear whether AR is a trigger or component cause for asthma, but AR is a source of diminished quality of life for individuals with asthma. Additionally, in individuals with both conditions, AR is associated with poorly controlled asthma, including more frequent asthma exacerbations and asthma-related emergency department (ED) visits, while treatment of AR is associated with fewer asthma-related hospital admissions and ED visits. ${ }^{11-14}$

Most cases of AR respond to pharmacotherapy, including oral antihistamines, decongestants, intranasal steroid (INS) sprays, intranasal antihistamine (INA) sprays, and immunotherapy. INSs and INAs are the primary medical therapies used and may alternatively be used as first-line monotherapy agents for patients with intermittent or mild persistent forms of AR. ${ }^{15}$

Despite the wide variety of therapies that exist, successful management of AR remains a challenge. Inadequate symptom control can often lead to dissatisfaction in patients taking prescription AR treatments, resulting in poor medication adherence or increasing reliance on over-the-counter medication. ${ }^{16}$ Escalation of medical management to include combination therapies is recommended for patients with more difficult to control disease, such as those with moderate-to-severe, persistent AR. ${ }^{15}$

Until recently, patients needing a stronger pharmaceutical treatment than INSs had limited options. A new treatment, the formulation of azelastine hydrochloride and fluticasone propionate used as a single spray (MP-AzeFlu), has become available for AR patients who need treatment with an INS and an INA. ${ }^{15}$ Previous research has demonstrated that this new MP-AzeFlu formulation has an excellent safety profile and has been shown to be more effective in controlling AR symptoms than other first-line therapies. ${ }^{17,18}$ While previous studies have examined the clinical effectiveness of MP-AzeFlu compared with other therapies, there is a paucity of research on the impact of this AR treatment regimen on health care resource utilization and costs.

The purpose of this study was to determine health care utilization and costs of patients with AR using MP-AzeFlu in comparison with those patients using the potential alternative free combination of INS spray and INA spray. In order to investigate this relationship, we performed a retrospective claims-based study of commercially insured individuals. Previous studies have likewise used insurance claims data to compare resource utilization and costs for medical treatments of AR..$^{19,20}$ We focus specifically on health care utilization and costs related to AR and asthma in AR patients treated with either MP-AzeFlu or the free combination of INS and INA.

\section{Methods}

\section{Data Source}

All data for the current study were from the Humana administrative claims database between September 1, 2011, and
March 31, 2014, for commercially insured patients. The database contained patient enrollment and medical and pharmacy claims data. Enrollment data included patient demographics such as age, sex, and geographic region. Medical claims data included diagnosis codes based on the International Classification of Diseases, Ninth Revision, Clinical Modification (ICD-9-CM) associated with medical encounters and financial information. Pharmacy claims included fill dates for prescriptions, national drug codes, and drug cost data. The current study was submitted and approved by Schulman Associates Institutional Review Board before study initiation.

\section{Patient and Cohort Selection}

Two cohorts of commercially insured patients were identified based on the type of intranasal treatment prescribedMP-AzeFlu or free-combination therapy (INS and INA). Patients in both cohorts had to have a prescription claim for either MP-AzeFlu or free-combination therapy between September 1, 2012, (corresponding to the month of launch of MP-AzeFlu) and September 30, 2013, with 1 claim for a diagnosis of AR (ICD-9-CM: 477.xx) or chronic rhinitis (ICD-9-CM: 472.0) between September 1, 2011, and March 31, 2014. The first prescription claim identified for patients was designated as their index date. The index date for the MP-AzeFlu cohort consisted of the first prescription claim for that treatment, while the free-combination therapy cohort index date was the first prescription claim for an INA and an INS that occurred within 7 days of each other or showed an overlap of prescriptions for 90 days. All patients included in the current study had to be newly initiating on either of the therapies. This meant there could be no claim for an intranasal treatment prior to the index date for any participant to be included. To ensure study patients had no prior intranasal therapy claims, inclusion criteria included a 12-month period of health care coverage with no prescriptions and pharmacy fills for intranasal therapy.

Further inclusion criteria consisted of patients being between the ages of 12 and 89 years and having at least 12 months pre- and 6 months post-index continuous enrollment. Patients were excluded from either cohort if they had 1 claim for a diagnosis at any point during the identification period (September 1, 2012, to September 30, 2013) for endstage renal disease (ICD-9-CM: 585.6), cancer (ICD-9-CM: 140.xx-172.xx and 174.xx-208.xx), pregnancy (ICD-9-CM: 630.xx-679.xx, V22.xx, and V23.xx), or organ transplant (ICD-9-CM: V42.xx); were older than 89 years; or had any claims for an INS or an INA within 1 year of the index date. Patients aged younger than 19 years and residing in Nebraska, Delaware, or Alabama were also excluded due to laws in those states prohibiting research using patients younger than 19 years. Figure 1 displays attrition counts for both study cohorts. 


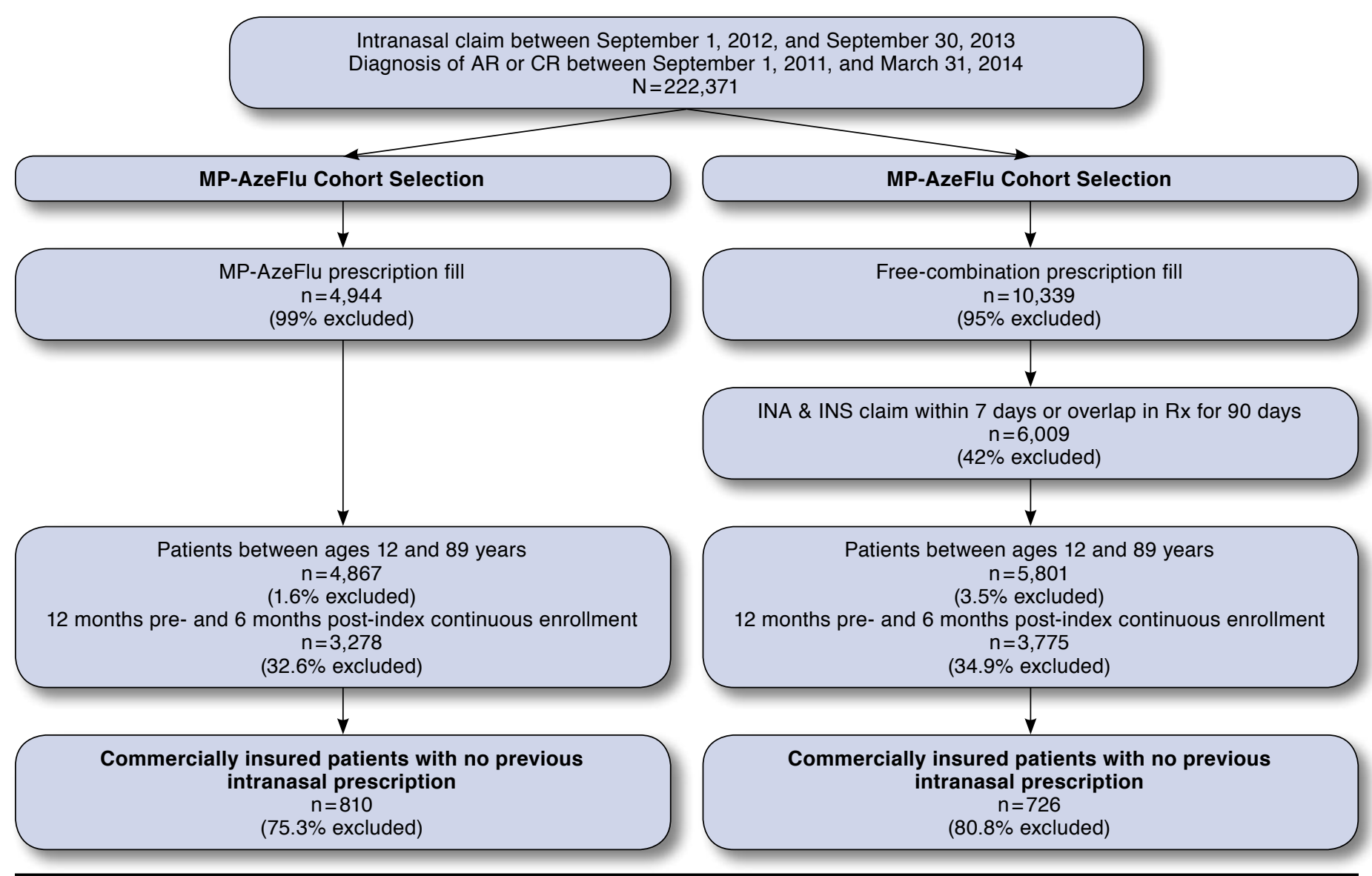

$A R=$ allergic rhinitis; $C R=$ chronic rhinitis; INA = intranasal antihistamine; INS = intranasal steroid; $R x=$ prescription

\section{Study Measures}

Demographic and Clinical Characteristics. Demographic and clinical characteristics were examined for the 12-month baseline period for patients in each cohort. Demographic characteristics included age, sex, and geographic locale. Geographic locale was further broken out by states with the largest plan populations (Florida, Georgia, Louisiana, Texas, Kentucky, and Tennessee) and then by regions (South, Midwest, Central, Mountain, East, Upper Midwest, and West). The season for each patient's index date was also tracked as winter (December, January, February); spring (March, April, May); summer (June, July, August); and fall (September, October, November).

Clinical characteristics included a Deyo-Charlson Comorbidity Index (DCCI) score that was calculated for each patient. ${ }^{21}$ Other pre-index conditions that were flagged and tracked included asthma (ICD-9-CM: 493.xx), acute sinusitis (ICD-9-CM: 461.xx), chronic sinusitis (ICD-9-CM: 473.xx), sleep apnea (ICD-9-CM: 327.23 and 780.57), nasal polyps
(ICD-9-CM: 471.xx), allergic rhinoconjunctivitis (ICD-9-CM: 372.14), and nonallergic conjunctivitis (ICD-9-CM: 372.05).

Health Care Resource Utilization. All-cause and AR-related health care resource utilization were calculated using all post-index medical and pharmacy claims. The index event was excluded from the post-index period. For the AR- and asthma-related utilization, only those medical and pharmacy claims associated with a diagnosis of AR or asthma were used. A diagnosis for AR or asthma could appear in any of the 9 diagnoses positions within the claims data. However, more than $90 \%$ of the claims for AR for the cohort patients were found in the primary position. Health care utilization was calculated for all 3 breakdowns (all-cause, AR-related, and asthma-related) for ED services, outpatient services, specialist visits, and pharmacy fills. ED services were assessed by counting the distinct service dates at an ED as defined by the place of treatment code found on the medical claim. Outpatient services included the count of distinct service dates and 
distinct providers for claims where the place of treatment is listed as outpatient. Specialist visits were a subset of outpatient visits where the provider is a specialist as specified by the physician specialty code on the claim. Pharmacy fills consisted of the count for distinct service dates (fill date) and national drug code. Pharmacy fills were normalized so that each fill could be equated to a 30-day supply. Furthermore, the INA and INS fill pairings for the free-combination cohort were counted as 1 fill for the index fill and all subsequent pharmacy fills. Both prescriptions were key for patients to be included in the cohort. By counting the combination of prescriptions as 1 fill, there would be no artificial representation by including each product as 1 fill.

For AR-related utilization, medical utilization was defined as any claim containing a diagnosis code for AR (ICD-9-CM: 477.0, 477.2 477.8, 477.9); chronic rhinitis (ICD-9-CM: 472.0); acute sinusitis (ICD-9-CM: 461.xx); or chronic sinusitis (ICD9-CM: 473.xx); or if the claim line procedure code was associated with allergy testing (Current Procedural Terminology, $4^{\text {th }}$ Edition [CPT-4]: 95004-95075) or allergy immunotherapy (CPT-4: 95115-95199). Pharmacy utilization was defined as any pharmacy claim for a product used to treat allergies (see Appendix for complete list, available in online article).

For asthma-related utilization, medical utilization was defined as any claim containing a diagnosis code for asthma (ICD-9-CM: 493.xx). Pharmacy utilization was defined as any claim for a product used to treat asthma (see Appendix for complete list).

Health Care Costs. Similar to calculations performed for health care utilization, all-cause, AR-related, and asthmarelated health care costs were calculated. Costs were examined for all medical, pharmacy, and total (sum of medical and pharmacy) costs. The allowable amount, defined as the amount remitted to the providers, found in the claims data was used in the analysis of health care costs for the current study. As in health care resource utilization, the index fill cost was excluded from the post-index period calculations with all postindex costs measured during the 6-month period following the index date for patients. All health care costs were adjusted to 2013 dollars, as it was the last complete calendar year for the study observation. The medical consumer price index is used for the adjustment.

\section{Statistical Analysis}

All analyses were conducted using SAS software package 9.3 (SAS Institute, Cary, NC). For the demographic and clinical characteristics, means and standard deviations were calculated for continuous variables. For any categorical variables, counts and percentages were calculated. For the demographic and clinical characteristics, comparisons between the cohorts were conducted using t-tests for all continuous variable data and chisquare tests for all categorical data.
To minimize the risk of selection bias for the 2 cohorts before computing any outcome measures, inverse propensity treatment score weighting (IPTW) was employed. ${ }^{22}$ IPTW was used to balance the differential characteristics of patient cohorts. Age, sex, DCCI and other comorbid conditions, geographic region, and season were the characteristics that contributed to the weights used for the IPTW adjustment. Unadjusted (scores prior to matching) and adjusted (scores following matching) results are presented for demographic and clinical baseline characteristics. All health care resource utilization and cost outcomes presented are adjusted.

Generalized linear models using a log-link function and gamma distribution were generated to assess health care costs, and linear regression models were generated to assess measures of health care utilization as our dependent variables and AR treatment (MP-AzeFlu vs. the free-combination therapy) as the independent variable. The demographic and clinical characteristics identified for patients in each cohort were included in the models as covariates. Least squares means were computed for both utilization and costs. Along with the IPTW adjustment, the least squares means for utilization and costs were also adjusted for prescriber type (general practitioner, specialist, or unknown), switching status (whether the patient switched treatments during the post-index period), and preindex total costs (used when looking at all 3 categories of cost post-index). Significance for all analyses was set at a 0.05 alpha level a priori.

\section{Results}

Figure 1 shows the selection criteria and final attrition counts for each of the study cohorts. A total of 222,371 patients with a diagnosis of AR or chronic rhinitis were initially identified. Of those patients, 810 had an index prescription for MP-AzeFlu, and 726 had an index prescription for the free-combination therapy.

\section{Demographic and Clinical Characteristics}

Table 1 shows unadjusted and IPTW-adjusted baseline (12 months prior to index prescription) demographic and clinical characteristics for the MP-AzeFlu and free-combination cohorts. In an examination of the unadjusted descriptive results, the mean age for patients in both cohorts was 42 years, and $43 \%$ MP-AzeFlu and 45\% free-combination patients were male. Of the geographic regions served by the health plan, the largest representation of patients was found in the South for both the MP-AzeFlu and free-combination cohorts (85\% and $78 \%$, respectively), with the second largest found in the Midwest (10\% and $16 \%$ ). A very small sample of patients was located in the West (5\% and 6\%, respectively), and none were located in the Northeast. Overall mean DCCI scores were low for both the MP-AzeFlu and free-combination cohorts (0.19 and 0.22 , respectively). Of the other specific comorbid con- 
TABLE 1 Unadjusted and Adjusted Mean (Age) and Percentages for the Demographic and Clinical Characteristics for Both Study Cohorts in the Commercial Population

\begin{tabular}{|c|c|c|c|c|}
\hline & \multicolumn{2}{|c|}{ Unadjusted } & \multicolumn{2}{|c|}{ Adjusted } \\
\hline & MP-AzeFlu & Free Combination & MP-AzeFlu & Free Combination \\
\hline Total sample size & 810 & 726 & 810 & 726 \\
\hline Age, years, mean & 42.6 & 42.6 & 41.2 & 41.6 \\
\hline Sex, \% male & 43.2 & 45.2 & 40.0 & 40.6 \\
\hline \multicolumn{5}{|l|}{ Geographic region } \\
\hline South & 85.4 & 78.2 & 74.9 & 74.4 \\
\hline Northeast & 0.0 & 0.0 & 0.0 & 0.0 \\
\hline Midwest & 9.5 & 16.1 & 19.1 & 20.1 \\
\hline West & 5.1 & 5.6 & 6.0 & 5.5 \\
\hline \multicolumn{5}{|l|}{ Comorbidities } \\
\hline Asthma & 13.5 & 15.6 & 10.7 & 10.8 \\
\hline Acute sinusitis & 27.5 & 26.3 & 23.6 & 24.3 \\
\hline Chronic sinusitis & 16.9 & 15.6 & 11.3 & 9.9 \\
\hline Sleep apnea & 7.5 & 5.5 & 4.4 & 3.7 \\
\hline Nasal polyps & 1.7 & 2.3 & 1.3 & 0.9 \\
\hline Allergic rhinoconjunctivitis & 5.4 & 4.4 & 2.5 & 2.2 \\
\hline Nonallergic conjunctivitis & 1.6 & 1.5 & 1.3 & 1.3 \\
\hline DCCI, mean & 0.19 & 0.22 & 0.14 & 0.15 \\
\hline \multicolumn{5}{|c|}{ Regions used for propensity score } \\
\hline Florida & 15.9 & 11.4 & 14.9 & 15.8 \\
\hline Georgia & 10.5 & 9.4 & 7.7 & 8.5 \\
\hline Louisiana & 5.2 & 7.9 & 5.0 & 5.2 \\
\hline Texas & 37.9 & 38.4 & 31.9 & 31.8 \\
\hline Kentucky & 8.3 & 5.8 & 8.8 & 7.2 \\
\hline Tennessee & 4.9 & 4.0 & 4.1 & 3.5 \\
\hline South & 2.3 & 1.2 & 1.9 & 2.3 \\
\hline Midwest & 2.6 & 5.1 & 4.2 & 4.6 \\
\hline Central & 2.7 & 4.1 & 3.7 & 3.8 \\
\hline Mountain & 2.3 & 2.6 & 2.9 & 2.8 \\
\hline East & 0.0 & 0.0 & 0.0 & 0.0 \\
\hline Upper Midwest & 4.6 & 7.0 & 11.8 & 11.8 \\
\hline West & 2.7 & 3.0 & 3.1 & 2.7 \\
\hline \multicolumn{5}{|l|}{ Seasons } \\
\hline Winter & 28.3 & 27.7 & 24.8 & 24.3 \\
\hline Spring & 31.5 & 23.6 & 28.7 & 28.2 \\
\hline Summer & 22.7 & 19.6 & 18.7 & 18.4 \\
\hline Fall & 17.5 & 29.2 & 27.8 & 29.1 \\
\hline
\end{tabular}

ditions tracked, acute sinusitis (28\% and 26\%, respectively), asthma (14\% and 16\%), and chronic sinusitis (17\% and 16\%) were the most common among both cohorts. Small percentages of patients also suffered from sleep apnea, allergic rhinoconjunctivitis, and nasal polyps (between $2 \%$ and $8 \%$ ). The majority of patients received their index prescription during the fall, winter, and spring months of the identification period, with the fewest patients receiving index prescriptions during the summer months (June, July, and August). After IPTW adjustments were applied, the demographic and clinical characteristics were well matched.

\section{Health Care Resource Utilization}

Health care utilization was examined using all medical and pharmacy claims (all-cause utilization) as well as for AR-related claims during the 6 months following patients' index prescription. Table 2 shows the least squares means for 4 utilization categories examined across the 2 cohorts. With respect to allcause utilization, patients in the MP-AzeFlu cohort had slightly fewer ED visits (0.30) and outpatient services (7.96) than those in the free-combination cohort (ED visits, 0.38 and outpatient services, 8.06), but these comparisons were not statistically significant (ED, $P=0.255$; outpatient services, $P=0.624$ ). Patients in both cohorts had approximately 5 specialist visits during the 
TABLE 2 Six-Month Health Care Resource Utilization Least Squares Means for Each Study Cohort for All-Cause and Allergic Rhinitis-Related Utilization

\begin{tabular}{|c|c|c|c|c|c|c|}
\hline & \multicolumn{3}{|c|}{ All-Cause Related } & \multicolumn{3}{|c|}{ Allergic Rhinitis Related } \\
\hline & MP-AzeFlu & Free Combination & \multirow[b]{2}{*}{$P$ Value $^{\mathrm{a}}$} & MP-AzeFlu & Free Combination & \multirow[b]{2}{*}{$P$ Value } \\
\hline & $\mathrm{N}=810$ & $\mathrm{~N}=726$ & & $\mathrm{~N}=810$ & $\mathrm{~N}=726$ & \\
\hline Emergency department visits & 0.30 & 0.38 & 0.255 & 0.00 & 0.01 & $\mathrm{~b}$ \\
\hline Outpatient services & 7.96 & 8.06 & 0.624 & 2.13 & 1.81 & 0.139 \\
\hline Specialist visits & 5.33 & 5.25 & 0.814 & 1.73 & 1.53 & 0.117 \\
\hline Pharmacy fills & 11.26 & 12.97 & $<0.001$ & 1.01 & 1.17 & $<0.001$ \\
\hline
\end{tabular}

aP values for health care resource utilization were found using linear regression.

${ }^{b}$ Because there were no claims for emergency department visits for the MP-AzeFlu cohort, there was no statistical test performed and therefore no P value to report.

6 months following their AR diagnosis and index therapy prescription. However, patients in the free-combination cohort had significantly more pharmacy fills $(12.97 ; \mathrm{P}<0.001)$ following their index prescription than those using MP-AzeFlu (11.26).

With respect to AR-related utilization, patients in the MP-AzeFlu cohort had slightly more outpatient services (2.13) and specialist visits (1.73) related to AR than the free-combination cohort (1.81 and 1.53, respectively), but this was not statistically significant (outpatient services, $P=0.139$; specialist visits, $P=0.117$ ). Neither cohort had claims for ED visits during the 6 months after filling the index therapy. Just as with the all-cause analysis, patients in the free-combination cohort had significantly more AR-related pharmacy fills post-index (1.17) than the MP-AzeFlu cohort $(1.01 ; P<0.001)$.

\section{Health Care Costs}

Health care costs were likewise classified as all-cause or AR-related. These costs included all pertinent medical, pharmacy, and total (the sum of medical and pharmacy) costs. Table 3 shows the least squares means for these costs in the MP-AzeFlu and free-combination cohorts. Total pharmacy costs (excluding the index fills for MP-AzeFlu or free combination of drugs) for the MP-AzeFlu cohort (\$729) were significantly lower than for the free-combination cohort $(\$ 1,094$; $P<0.001)$. Total medical costs and total costs were significantly lower $(P=0.003$ and $P<0.001$, respectively) for the MP-AzeFlu patients $(\$ 2,161$ and $\$ 2,890$, respectively) than for the freecombination patients ( $\$ 2,315$ and $\$ 3,409$, respectively).

AR-related pharmacy costs were significantly lower $(P<0.001)$ for the MP-AzeFlu cohort $(\$ 128)$ compared with the free-combination cohort (\$268). If the cost of the nasal spray fills on the index dates is included, the mean AR-related pharmacy costs increase about $\$ 150$-from $\$ 128$ to $\$ 279$ for the MP-AzeFlu cohort and from $\$ 268$ to $\$ 418$ for the freecombination cohort, and this cost differential between the 2 cohorts remains statistically significant $(P=0.048)$. AR-related medical costs were similar for the MP-AzeFlu patients (\$206) and the patients in the free-combination cohort (\$190) 6 months following their index prescription fill, and this was not statistically significant $(P=0.454)$. Total costs were also lower for the MP-AzeFlu cohort patients (\$334) than for the free-combination cohort $(\$ 458 ; P=0.001)$. This difference in total costs remains quantitatively similar and statistically significant even if the cost of the nasal spray fills on the index date is included.

\section{Asthma-Related Utilization and Costs}

Patients in both cohorts with a concurrent diagnosis of asthma were examined separately for utilization and costs. Of the originally identified cohorts, 109 patients on MP-AzeFlu and 113 patients on the free-combination therapy also had a diagnosis of asthma. For these patients, asthma-related claims (both medical and pharmacy) were assessed and are reported in Table 4. Asthma-related utilization mirrored our findings for all-cause utilization. Patients in the MP-AzeFlu cohort had slightly fewer outpatient services (0.98) and specialist visits (0.80) than the free-combination cohort ( 1.30 and 0.87 , respectively), and these differences were not statistically significant (outpatient services, $P=0.221$; specialist visits, $P=0.410$ ). ED visits were similar across both cohorts. Free-combination patients also had significantly more prescription fills (3.35) than the MP-AzeFlu cohort patients (1.50) following the index day $(P<0.001)$.

Total pharmacy costs were significantly higher $(P=0.008)$ for the free-combination cohort patients (\$928) than for the MP-AzeFlu patients (\$192). Total medical costs were low but similar for the MP-AzeFlu cohort (\$351) and free-combination cohort ( $\$ 333 ; P>0.100)$. Total costs were significantly higher for the free-combination cohort $(\$ 1,260)$ than for the MP-AzeFlu cohort $(\$ 543 ; P=0.020)$.

\section{Discussion}

This retrospective claims-based study examined the health care resource utilization and costs associated with AR for patients treated with MP-AzeFlu or concurrent, free-combination therapy with single-ingredient INA and INS sprays. Because AR is one of the most chronic conditions among the U.S. population, finding the appropriate therapy to relieve AR symptoms 


\section{TABLE 3 Six-Month Health Care Costs Least Squares Means for Each Study Cohort for} All-Cause and Allergic Rhinitis-Related Costs

\begin{tabular}{|c|c|c|c|c|c|c|}
\hline & \multicolumn{3}{|c|}{ All-Cause Related } & \multicolumn{3}{|c|}{ Allergic Rhinitis Related } \\
\hline & MP-AzeFlu & Free Combination & \multirow[b]{2}{*}{$P$ Value ${ }^{\mathrm{a}}$} & MP-AzeFlu & Free Combination & \multirow[b]{2}{*}{$P$ Value } \\
\hline & $\mathrm{N}=810$ & $\mathrm{~N}=726$ & & $\mathrm{~N}=810$ & $\mathrm{~N}=726$ & \\
\hline Pharmacy costs & $\$ 729$ & $\$ 1,094$ & $<0.001$ & $\$ 128$ & $\$ 268$ & $<0.001$ \\
\hline Medical costs & $\$ 2,161$ & $\$ 2,315$ & 0.003 & $\$ 206$ & $\$ 190$ & 0.454 \\
\hline Total costs & $\$ 2,890$ & $\$ 3,409$ & $<0.001$ & $\$ 334$ & $\$ 458$ & 0.001 \\
\hline
\end{tabular}

aP values for health care costs were found using generalized linear models.

and reduce AR-associated health care costs is of societal importance. The results for this study suggest that health care resource utilization and costs are different for those patients taking MP-AzeFlu than for those patients prescribed both an INA and an INS. Specifically, we found that AR patients who were treated with MP-AzeFlu experienced fewer all-cause, AR-related, and asthma-related pharmacy fills, and lower all-cause, AR-related, and asthma-related pharmacy costs compared with patients on free-combination therapy with an INA and an INS.

There are many studies that speak to the efficacy and safety of MP-AzeFlu for patients with moderate-to-severe seasonal allergies. ${ }^{17}$ However, since MP-AzeFlu is a new intranasal therapy, its impact on health care resource utilization and costs has not been assessed until now. This is the first study to examine how patients taking this particular therapy compared with similar patients on a free combination of INA and INS drugs.

Current research shows that there is an incremental increase in the utilization and costs for individuals diagnosed with AR. ${ }^{23}$ Our findings for health care utilization and costs for AR patients taking the free combination of therapies are similar to those found in other studies. In a 2011 study by Bhattacharyya, ${ }^{23}$ patients with AR averaged 3.25 office visits, 8.95 prescription fills, more than $\$ 1,400$ in total costs, and $\$ 876$ in pharmacy costs annually, which are similar to results found here for all-cause costs and utilization by AR patients on a free combination of INA and INS but are higher than costs we have found to be incurred by AR patients on MP-AzeFlu. (MP-AzeFlu became available in 2012 and therefore was not included in previous studies of health care utilization and costs.) In order for any significant difference to occur between these 2 cohorts, there needed to be a large difference in the count of utilization services. While the free-combination cohort had higher means for ED visits and outpatient services, this did not equate to significantly higher utilization. However, the higher count of services would be associated with higher costs, since 1 ED visit can generate higher costs.

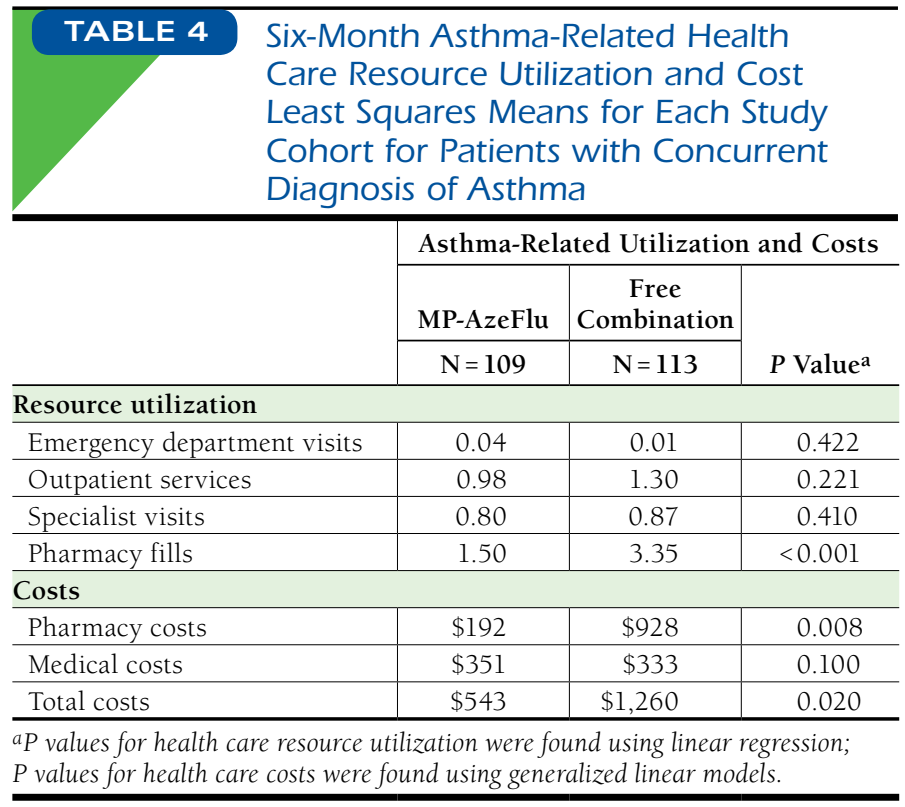

We additionally found that AR-related pharmacy costs were lower in patients on MP-AzeFlu than in patients on the free combination of INA and INS. Previous arguments made by third-party payers against the use of MP-AzeFlu were based on the immediate and direct cost associated with MP-AzeFlu relative to the free combination of INA and INS. However, this approach does not take long-term costs into consideration. We found that patients on the free combination of INA and INS had more prescription fills for their nasal sprays over our study period. Additionally, over time, AR-related pharmacy costs are only partially composed of either the cost of MP-AzeFlu or the free combination of an INS and an INA. AR-related pharmacy costs consisting of other medications such as decongestants or nasal treatments such as saline irrigations must also be considered.

In our study, AR patients on the free combination of INA and INS may have used more expensive ancillary AR-related therapeutics to supplement their INA and INS, which led to higher overall AR-related pharmacy costs in comparison with 
patients using MP-AzeFlu. The decision was made to exclude the index fill cost from all analyses, as this helped to ensure a clearer examination of all post-index outcomes. While there are arguments to include the index fill, the only impact of including this cost was found for pharmacy utilization, where the fill count increased by 1 for both groups. The health care costs increased for both groups, but the cost differential between the groups was identical and the statistical difference was the same.

Interestingly, we also found lower asthma-related health care utilization and pharmacy costs in AR patients with asthma on MP-AzeFlu compared with those on the INA and INS free combination. The "unified airway hypothesis" suggests that upper and lower airway inflammation may be linked and that the exacerbation of one may in turn lead to exacerbation of the other. ${ }^{24-26}$ One explanation for the finding that the MP-AzeFlu cohort had lower asthma-related pharmacy costs could be better control of AR by MP-AzeFlu, leading to better asthma control, although this remains speculation at this point and other explanations may exist.

\section{Limitations}

This study has several limitations that should be considered when interpreting the current findings. These findings are only applicable to the members identified in the study population. Additionally, the analyses were only completed for those patients who had newly initiated to MP-AzeFlu or a free combination of products. The study did not examine patients in the Medicaid population, who have previously been shown to have different utilization patterns and severity of disease than patients with private insurance (commercial) or Medicare coverage. ${ }^{27-29}$ When examining utilization and costs, only 6 months of data were available for use, which may not be comparable to other studies on AR treatments that used 12 months of post-index data.

While there is a case to be made for using prevalent AR patients, by focusing on new initiators, confounders to subsequent utilization associated with the effects of previous nasal spray use were removed. The analyses performed here were also completed for all members, not just new initiators, and results were similar to those presented here.

The severity of AR-related symptoms or asthma, which is not available in claims databases, could also not be accounted for in this study. The relative similarity in unadjusted frequency of atopic comorbidities such as acute and chronic sinusitis and nasal polyps between the MP-AzeFlu and free-combination cohorts suggests that on the whole these 2 cohorts were similar. However, the definitive lack of AR and asthma severity nonetheless potentially confounds our results. Also, as this is a retrospective claims-based study, based on the patterns of a select sample of patients, no causal inferences can be ascertained from the results. Because these results are limited to a specific cohort of commercially insured patients at a large health plan, they cannot be generalized to the larger, external population.
Adherence was not an outcome of interest for this study, partly because patients' utilization may vary as a function of the severity of the symptoms they experience, and the severity of AR is not available on claims data.

Finally, pharmacy costs included for analyses were limited to the medications that require a prescription and could be found in the pharmacy claims, leaving over-the-counter medication treatments out.

\section{Conclusions}

In a comprehensive claims database of commercially insured patients with AR requiring dual therapy with an INA and an INS, we found the cohort taking MP-AzeFlu had lower overall, AR-related, and asthma-related health care utilization and costs compared with a matched cohort taking the free combination of an INA and an INS. MP-AzeFlu may offer advantages with respect to medical costs, in particular, AR- and asthma-related pharmacy costs, over the free combination of INA and INS. At the very least, MP-AzeFlu does not appear to be associated with higher costs. This information should be considered when treating AR patients who require dual INS and INA therapy, in particular, those with asthma.

\section{Authors}

BROOKE HARROW, PhD, Meda Pharmaceuticals, Somerset, New Jersey, and AHMAD R. SEDAGHAT, MD, PhD, Department of Otolaryngology, Harvard Medical School, Massachusetts Eye and Ear Infirmary, Boston, Massachusetts. ROBERT DUFOUR, PhD, and AMANDA CALDWELL-TARR, PhD, Comprehensive Health Insights, Louisville, Kentucky.

AUTHOR CORRESPONDENCE: Amanda Caldwell-Tarr, PhD, 515 W. Market St., Louisville, KY 40202. Tel.: 502.476.8343; Fax: 502.405.6133; E-mail: atarr1@humana.com.

\section{DISCLOSURES}

This study was funded by Meda Pharmaceuticals. Authors were either employed by Meda Pharmaceuticals or received consulting fees from Meda Pharmaceuticals. Comprehensive Health Insights and Sedaghat received funding from Meda Pharmaceuticals as a consultant to participate in this study. Dufour and Caldwell-Tarr are employees of Comprehensive Health Insights. Harrow is currently employed by TESARO.

This study was conceived by Harrow, Dufour, and Caldwell-Tarr. All authors contributed to the design of the study. Dufour took the lead in data collection, along with Caldwell-Tarr, and data interpretion was performed by Harrow, along with the other authors. Analyses were performed by Dufour. The manuscript was written and revised by all authors.

\section{ACKNOWLEDGMENTS}

The authors acknowledge the work of Ullrich Munzel, PhD; Larry Gever, PharmD; and Jeffrey Hofmeister, BA (all employees of Meda Pharmaceuticals) for their support and contributions to the study design, analyses, and manuscript production. 


\section{REFERENCES}

1. Togias AG. Systemic immunologic and inflammatory aspects of allergic rhinitis. J Allergy Clin Immunol. 2000;106(5 Suppl):S247-50.

2. Khan DA. Allergic rhinitis and asthma: epidemiology and common pathophysiology. Allergy Asthma Proc. 2014;35(5):357-61

3. Meltzer EO, Blaiss MS, Derebery MJ, et al. Burden of allergic rhinitis: results from the Pediatric Allergies in America survey. J Allergy Clin Immunol. 2009;124(3 Suppl):S43-70. Available at: http://www.jacionline.org/article/ S0091-6749(09)00804-5/fulltext. Accessed August 8, 2016.

4. Tran NP, Vickery J, Blaiss MS. Management of rhinitis: allergic and nonallergic. Allergy Asthma Immunol Res. 2011;3(3):148-56. Available at: http://eaair.org/DOIx.php?id=10.4168/aair.2011.3.3.148. Accessed August 8, 2016.

5. American College of Allergy, Asthma, and Immunology. Allergy facts. Available at: http://acaai.org/news/facts-statistics/allergies. Accessed August 8, 2016

6. Nathan R. The burden of allergic rhinitis. Allergy Asthma Proc. 2007;28(1):3-9.

7. Blaiss MS. Quality of life in allergic rhinitis. Ann Allergy Asthma Immunol. 1999;83(5):449-54

8. Thompson AK, Juniper E, Meltzer EO. Quality of life in patients with allergic rhinitis. Ann Allergy Asthma Immunol. 2000;85(5):338-47.

9. Meltzer EO. Allergic rhinitis: burden of illness, quality of life, comorbidities, and control. Immunol Allergy Clin North Am. 2016;36(2):235-48.

10. Mehta P. Allergic rhinitis and bronchial asthma. J Assoc Physicians India. 2014;62(3 Suppl):23-26

11. Bousquet J, Gaugris S, Kocevar VS, et al. Increased risk of asthma attacks and emergency visits among asthma patients with allergic rhinitis: a subgroup analysis of the investigation of montelukast as a partner agent for complementary therapy [corrected]. Clin Exp Allergy. 2005;35(6):723-27.

12. Crystal-Peters J, Neslusan C, Crown WH, Torres A. Treating allergic rhinitis in patients with comorbid asthma: the risk of asthma-related hospitalizations and emergency department visits. J Allergy Clin Immunol. 2002;109(1):57-62

13. Corren J, Manning BE, Thompson SF, Hennessy S, Strom BL. Rhinitis therapy and the prevention of hospital care for asthma: a case-control study. J Allergy Clin Immunol. 2004;113(3):415-19.

14. Thomas M, Kocevar VS, Zhang Q, Yin DD, Price D. Asthma-related health care resource use among asthmatic children with and without concomitant allergic rhinitis. Pediatrics. 2005;115(1):129-34.

15. Brozek JL, Bousquet J, Baena-Cagnani CE, et al. Allergic Rhinitis and its Impact on Asthma (ARIA) guidelines: 2010 revision. J Allergy Clin Immunol. 2010;126(3):466-76. Available at: http://www.jacionline.org/article/S00916749(10)01057-2/fulltext. Accessed August 8, 2016.
16. Meltzer EO, Bukstein DA. The economic impact of allergic rhinitis and current guidelines for treatment. Ann Allergy Asthma Immunol. 2011;106 (2 Suppl):S12-16. Available at: http://www.annallergy.org/article/S10811206(10)00958-0/fulltext. Accessed August 8, 2016.

17. Bousquet J, Bachert C, Bernstein J, et al. Advances in pharmacotherapy for the treatment of allergic rhinitis; MP29-02 (a novel formulation of azelastine hydrochloride and fluticasone propionate in an advanced delivery system) fills the gaps. Expert Opin Pharmacother. 2015;16(6):913-28.

18. Bernstein JA. MP29-02: a breakthrough for the treatment of allergic rhinitis. Expert Opin Pharmacother. 2013;14(15):2101-13.

19. Hay J, Jhaveri M, Tangirala M, Kaliner M. Cost and resource utilization comparisons of second-generation antihistamines vs. montelukast for allergic rhinitis treatment. Allergy Asthma Proc. 2009;30(6):634-42.

20. Fairchild CJ, Durden E, Cao Z, Smale P. Outcomes and cost comparison of three therapeutic approaches to allergic rhinitis. Am J Rhinol Allergy. 2011;25(4):257-62.

21. Deyo RA, Cherkin DC, Ciol MA. Adapting a clinical comorbidity index for use with ICD-9-CM administrative databases. J Clin Epidemiol. 1992;45(6):613-19.

22. Leslie, RS. Using propensity scores to adjust for treatment selection bias. Proceedings of the SAS Global Forum 2007 Conference. Cary, NC: SAS Institute Inc.; 2007. Available at: http://www2.sas.com/proceedings/forum2007/1842007.pdf. Accessed August 16, 2016.

23. Bhattacharyya N. Incremental healthcare utilization and expenditures for allergic rhinitis in the United States. Laryngoscope. 2011;121(9):1830-33.

24. Feng $\mathrm{CH}$, Miller MD, Simon RA. The united allergic airway: connections between allergic rhinitis, asthma, and chronic sinusitis. Am J Rhinol Allergy. 2012;26(3):187-90. Available at: http://www.ncbi.nlm.nih.gov/pmc/articles/ PMC3906509/. Accessed August 8, 2016.

25. Sedaghat AR, Gray ST, Chambers KJ, Wilke CO, Caradonna DS Sinonasal anatomic variants and asthma are associated with faster development of chronic rhinosinusitis in patients with allergic rhinitis. Int Forum Allergy Rhinol. 2013;3(9):755-61.

26. Sedaghat AR, Phipatanakul W, Cunningham MJ. Prevalence of and associations with allergic rhinitis in children with chronic rhinosinusitis. Int J Pediatr Otorhinolaryngol. 2014;78(2):343-47. Available at: http://www.ncbi. nlm.nih.gov/pmc/articles/PMC3966022/. Accessed August 8, 2016.

27. Sedaghat AR, Wilke CO, Cunningham MJ, Ishman SL. Socioeconomic disparities in the presentation of acute bacterial sinusitis complications in children. Laryngoscope. 2014;124(7):1700-06.

28. Scangas GA, Ishman SL, Bergmark RW, Cunningham MJ, Sedaghat AR. Emergency department presentation for uncomplicated acute rhinosinusitis is associated with poor access to healthcare. Laryngoscope. 2015;125(10):2253-58.

29. Access of Medicaid recipients to outpatient care. N Engl J Med. 1994;330(20):1426-30 
APPENDIX Allergic Rhinitis and Asthma-Related Treatments for Pharmacy Utilization

AR-Related Treatments

ACRIVASTINE \& PSEUDOEPHEDRINE

ALCAFTADINE OPHT

AZELASTINE HCL NASAL

AZELASTINE HCL-FLUTICASONE PROP NASAL

BECLOMETHASONE DIPROPIONATE NASAL

BROMPHENIRAMINE \& PHENYLEPHRINE

BROMPHENIRAMINE \& PSEUDOEPHEDRINE

BROMPHENIRAMINE MALEATE

BUDESONIDE NASAL

CARBINOXAMINE MALEATE

CETIRIZINE HCL

CETIRIZINE-PSEUDOEPHEDRINE

CHLORCYCLIZINE \& PSEUDOEPHEDRINE

CHLORCYCLIZINE HCL

CHLORCYCLIZINE-PHENYLEPHRINE

CHLORPHEN-PE-METHSCOPOLAMINE

CHLORPHEN-PHENYLEPHRINE W/ APAP

CHLORPHEN-PYRILAMINE \& PE

CHLORPHENIRAMINE \& PHENYLEPHRINE

CHLORPHENIRAMINE \& PSEUDOEPHEDRINE

CHLORPHENIRAMINE MALEATE

CHLORPHENIRAMINE W/CODEINE

CHLORPHENIRAMINE-ACETAMINOPHEN

CHLORPHENIRAMINE-DM

CHLORPHENIRAMINE-PSEUDOEPHEDRINE-IBUPROFEN

CICLESONIDE NASAL

CLEMASTINE FUMARATE

CROMOLYN SODIUM OPHT

CYPROHEPTADINE HCL

DESLORATADINE \& PSEUDOEPHEDRINE

DESLORATADINE

DEXBROMPHENIRAMINE MALEATE

DEXBROMPHENIRAMINE-PHENYLEPHRINE

DEXCHLORPHENIRAMINE \& PSEUDOEPHEDRINE

DEXCHLORPHENIRAMINE-PHENYLEPHRINE

DIPHENHYDRAMINE HCL

DOXYLAMINE-PSEUDOEPHEDRINE

EPINASTINE HCL OPHT

FEXOFENADINE HCL

FEXOFENADINE-PSEUDOEPHEDRINE

FLUNISOLIDE NASAL

FLUTICASONE FUROATE NASAL

FLUTICASONE PROPIONATE NASAL

IPRATROPIUM BROMIDE NASAL

LEVOCETIRIZINE DIHYDROCHLORIDE

LORATADINE \& PSEUDOEPHEDRINE

LORATADINE

LORATADINE/PSEUDOEPHEDRINE

LOTEPREDNOL ETABONATE OPHT

METHYLPREDNISOLONE

MOMETASONE FUROATE NASAL

MONTELUKAST SODIUM

OLOPATADINE HCL NASAL

OMALIZUMAB

OXYMETAZOLINE HCL

PHENYLEPH-PYRILAMINE-CHLOPHEDIANOL

PHENYLEPHRINE HCL

PHENYLEPHRINE W/DM-GG

PHENYLEPHRINE-BROMPHEN W/ CODEINE

PHENYLEPHRINE-BROMPHEN-DIHYDROCODEINE

PHENYLEPHRINE-BROMPHENIRAMINE-DM

PHENYLEPHRINE-CHLORPHEN-DM

PHENYLEPHRINE-DEXBROMPHEN-CHLOPHEDIANOL

PHENYLEPHRINE-PYRILAMINE-DM
PREDNISOLONE SOD PHOSPHATE

PREDNISONE

PSEUDOEPHED-BROMPHEN-DM

PSEUDOEPHED-CHLORPHEN-CHLOPHEDIANOL

PSEUDOEPHED-CHLORPHEN-DM

PSEUDOEPHED-DEXBROMPHENIRAMINE-DM

PSEUDOEPHED-DEXCHLORPHEN-CHLOPHEDIANOL

PSEUDOEPHED-DOXYLAMINE-DM

PSEUDOEPHEDRINE HCL

PSEUDOEPHEDRINE W/COD-GG

PSEUDOEPHEDRINE W/DM-GG

PSEUDOEPHEDRINE-DM-GG W/APAP

PYRILAMINE MAL-PHENYLEPHRINE HCL

PYRILAMINE-PHENYLEPHRINE

SALINE NASAL

THONZYLAMINE-PHENYLEPHRINE

TRIAMCINOLONE ACETONIDE NASAL

ZAFIRLUKAST

Asthma-Related Treatments

ACLIDINIUM BROMIDE

ALBUTEROL SULFATE

ALBUTEROL-IPRATROPIUM

AMINOPHYLLINE

AMINOPHYLLINE-EPHEDRINE-AMOBARBITAL

AMINOPHYLLINE-EPHEDRINE-PB-GG

AMINOPHYLLINE-EPHEDRINE-PB-KI

AMINOPHYLLINE-KI

ARFORMOTEROL TARTRATE

ATROPINE SULFATE

BECLOMETHASONE DIPROPIONATE

BITOLTEROL MESYLATE

BUDESONIDE

BUDESONIDE-FORMOTEROL FUMARATE DIHYD

CICLESONIDE

CLENBUTEROL HCL

CROMOLYN SODIUM

DEXAMETHASONE SODIUM PHOSPHATE

DYPHYLLINE

DYPHYLLINE-GG

DYPHYLLINE-EPHEDRINE-PB-GG

DYPHYLLINE-GUAIFENESIN

EPHEDRINE HCL

EPHEDRINE SULFATE

EPINEPHRINE BITARTRATE

EPINEPHRINE HCL

EPHEDRINE-KI

ETHYLNOREPINEPHRINE

FLUNISOLIDE HFA

FLUTICASONE FUROATE

FLUTICASONE FUROATE-VILANTEROL

FLUTICASONE PROPIONATE

FLUTICASONE-SALMETEROL

FORMOTEROL FUMARATE

GLYCOPYRROLATE

INDACATEROL MALEATE

INDACATEROL-GLYCOPYRROLATE

IPRATROPIUM BROMIDE HFA

IPRATROPIUM-ALBUTEROL

ISOETHARINE HCL

ISOETHARINE MESYLATE

ISOPROTERENOL \& PHENYLEPHRINE

ISOPROTERENOL HCL

ISOPROTERENOL SULFATE

ISOPROTERENOL 
A Comparison of Health Care Resource Utilization and Costs for Patients with Allergic Rhinitis on Single-Product or Free-Combination Therapy of Intranasal Steroids and Intranasal Antihistamines

APPENDIX Allergic Rhinitis and Asthma-Related Treatments for Pharmacy Utilization (continued)

LEVALBUTEROL HCL

MEPOLIZUMAB

METAPROTERENOL SULFATE

MOMETASONE FUROATE

MONTELUKAST SODIUM

NEDOCROMIL SODIUM

OLODATEROL HCL

OMALIZUMAB

OXTRIPHYLLINE

OXTRIPHYLLINE-GUAIFENESIN

PIRBUTEROL ACETATE

RACEPINEPHRINE HCL

RESLIZUMAB IV

ROFLUMILAST

SALMETEROL XINAFOATE

TERBUTALINE SULFATE

THEO CAL SAL-EPHEDRINE-PB-KI

THEO CAL SAL-EPHEDRINE-PB-KI

THEO SOD GLYC-EPHEDRINE-COD-GG

THEOPHYLLINE
THEOPHYLLINE SOD GLYCINATE-GG

THEOPHYLLINE-EPHED-BUTABARB-GG

THEOPHYLLINE-EPHEDRINE-GG

THEOPHYLLINE-EPHEDRINE-HYDROXYZINE

THEOPHYLLINE-EPHEDRINE-PB-GG

THEOPHYLLINE-EPHEDRINE-PHENOBARBITAL

THEOPHYLLINE-EPHEDRINE-PYRILAMINE-GG

THEOPHYLLINE-GUAIFENESIN

THEOPHYLLINE-IODINATED GLYCEROL

THEOPHYLLINE-KI ELIXIR

THEOPHYLLINE-PSE-BUTABARB-GG

THEOPHYLLINE-PSE-GG

TIOTROPIUM BR-OLODATEROL

TIOTROPIUM BROMIDE MONOHYDRATE

TRIAMCINOLONE ACETONIDE

UMECLIDINIUM BR

UMECLIDINIUM-VILANTEROL

ZAFIRLUKAST

ZILEUTON 